East African Medical Journal Vol. 80 No. 4 April 2003

PERCUTANEOUS TRANSVENOUS MITRAL COMMISSUROTOMY IN JUVENILE MITRAL STENOSIS

G.O. Yonga, MBChB, MMed, Consultant Cardiologist, Hurlingham Heart Clinic, P.O. Box 76555, Nairobi and P. Bonhoeffer, Consultant Cardiologist and Director

Paediatric Cardiology Department, The Great Ormond Street Hospital, London, U.K.

Request for reprints to: Dr. G.O. Yonga, Consultant Cardiologist, Hurlingham Heart Clinic, P.O. Box 76555, Nairobi, Kenya

\title{
PERCUTANEOUS TRANSVENOUS MITRAL COMMISSUROTOMY IN JUVENILE MITRAL STENOSIS
}

\section{G.O. YONGA and P. BONHOEFFER}

\begin{abstract}
Objective: To determine the efficacy and safety of percutaneous transvenous mitral commissurotomy(PTMC), using multi-track double balloon technique in juvenile mitral stenosis.

Design: Open non-randomised intervention.

Setting: Cardiac catheterisation laboratories of The Mater Hospital, The Nairobi Hospital and Kenyatta National Hospital from 1996 to 2001.

Patients: Forty five consecutive patients aged less than 21 years with severe pure mitral stenosis and suitable mitral valve apparatus (leaflets, chordae and papillary muscles) for successful commissurotomy.

Intervention: Percutaneous transvenous mitral commissurotomy under local anaesthesia. Standard left and right heart catheterisation for mitral valve disease. Trans-septal left atrial entry using standard septal puncture technique and left ventricular position secured by superstiff guide-wire. Double-balloon mitral valvotomy on single guide-wire using multi-track balloon catheters.

Main outcome measures: Mitral valve area, left atrial pressures, mitral regurgitation grade, NYHA functional class.

Results: Mitral valve area increased from $0.6 \pm 0.19 \mathrm{~cm}^{2}$ to $1.9 \pm 0.19 \mathrm{~cm}^{2}(\mathrm{p}<0.001)$, left atrial pressures from $30.5 \pm 3.9 \mathrm{mmHg}$ to $11.5 \pm 3.8 \mathrm{mmHg}(\mathbf{p}<0.001)$. Most patients NYHA functional class immediately improved from class III-IV to class I-II. There was no significant changes in grades of mitral regurgitation or significant complications related to the procedure. Conclusions: PTMC in juvenile mitral stenosis using the multi-track technique is safe and effective yielding satisfactory immediate results.
\end{abstract}

\section{INTRODUCTION}

Juvenile mitral stenosis is predominantly seen in developing countries where rheumatic fever is still very common(1,2). Mitral stenosis (MS) represents a different pattern of rheumatic fever characterised by a "smouldering" sub-clinical course with the majority of the lesions being diagnosed in older patients (fifth to sixth decade) than mitral regurgitation or aortic regurgitation of rheumatic origin $(3,4)$. However, in developing countries, MS progresses more rapidly, presumably due to either a more severe rheumatic injury or repeated episodes of carditis due to streptococcal infections, resulting in severe symptomatic MS in the early to mid-teenage and the early twenties(5). MS in the under 21 year olds, therefore, attests to severe rheumatic fever and also carries poorer prognosis. Patients exhibit severe pulmonary oedema, early severe pulmonary hypertension and eventually severe right ventricular failure. The most effective method of alleviating this poor prognostic end-stage disease is aggressive control of rheumatic fever in the community, in hospitals and clinics. However, there are many patients who present with already severe symptomatic MS at less than twenty one years of age and require intervention. Closed heart surgery with surgical commissurotomy has been the most common form of intervention in Kenya but this has now been replaced by percutaneous transvenous mitral commissurotomy (PTMC). Appropriate balloon sizes for very small patients due to age or cardiac cachexia has however been a significant problem with the previous balloon systems, especially the Inoue cathetar system. With the introduction of the multi-track balloon systems it has been possible to perform this intervention effectively with more ease and safety even in the smallest/youngest of patients such as those seen in developing countries like Kenya(6). The authors describe a series of uniquely young patients with MS and their interventions with PTMC using the multi-track system.

\section{MATERIALS AND METHODS}

Out of over 200 patients done PTMC so far, forty five patients aged less than 21 years underwent PTMC in three hospitals in Nairobi between 1996 and 2001 (namely The Mater Hospital, Kenyatta National Hospital and Nairobi Hospital). The majority were referred from other hospitals and health institutions outside Nairobi. They were all symptomatic patients (NYHA functional class II to IV) with severe mitral stenosis due to rheumatic heart disease. They all underwent transthoracic and trans-oesophageal echocardiography, electrocardiography chest $\mathrm{X}$-ray and pre-catheterisation laboratory tests. Wilkins score tests 
were used to determine leaflet suitability for valvotomy(7). Mitral valve areas were determined by both pressure half-time and plannimetry and average values used. Patients with more than $2+$ mitral regurgitation were excluded. The mitral annulus diameter was used to select dilating balloon sizes (sum of balloon diameter $=90-100 \%$ annulus diameter $)(8)$.

Left and right heart catheterisation was done under local anaesthesia. A sheath was inserted into the left femoral artery and pigtail catheter introduced to identify the aortic root and also monitor pressures. Transeptal puncture was then performed from the right femoral vein utilising Mullin's dilator sheath system and Brockenbrough needle in the standard method. Heparin IV $100 \mathrm{iu} / \mathrm{kg}$ (or 5,000 iu for $>50 \mathrm{~kg}$ ) was then given. After simultaneous LA-LV pressure recordings, (figure 1) mitral valve dilatation was done using the multi-track double balloon technique (figure 2)(8,9).

Figure 1

Multi-track double baloon mitral dilatation

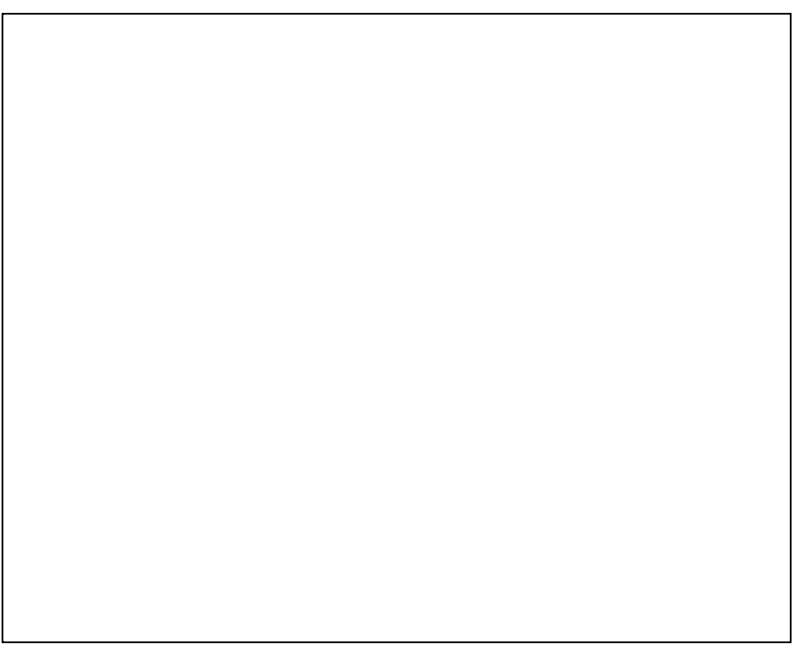

Figure 2

LA-LV Pressure gradient before and after PTMC

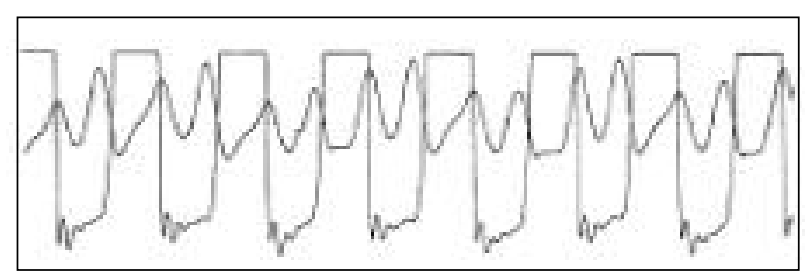

Before PTMC

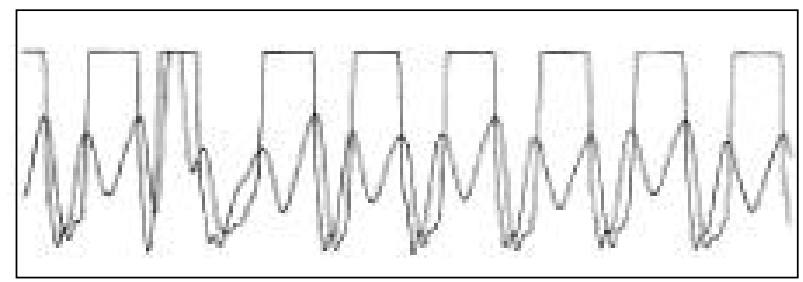

After PTMC
The LA-LV pressures were repeated and the procedure concluded. After 24 hours observation in hospital, the patients were discharged home for follow up. Post PTMC echocardiograms were performed before discharge and follow up appointments scheduled at six monthly then annually or otherwise according to area of residence.

\section{RESULTS}

The patients were aged 9-20 years (mean 14 \pm 2.6 ), comprising of 16 boys and 29 girls. They were all symptomatic and presented in NYHA functional class II to IV. They weighed between $18-57 \mathrm{Kg}$ (mean $35 \pm 10.3 \mathrm{~kg}$ ). Nine patients had active rheumatic fever at the time of presentation and needed bed rest, anti-inflammatory drugs and antibiotics treatments prior to PTMC. All the selected cases for PTMC did not have significant lesions on the other valves except for three cases where combined mitral and aortic stenosis was present and balloon dilatation for both valves was done at the same time. Eight of the patients had atrial fibrillation and of these three had thrombi in the left atrial appendage. No patients in sinus rhythm exhibited left atrial thrombi on transoesophaged echocardiography. On echocardiography all the patients had mitral valve areas of less than $1.0 \mathrm{~cm}^{2}$. Twenty five patients $(56 \%)$ had estimated pulmonary artery pressure (by tricuspid regurgitation jet velocity) greater than $75 \mathrm{mmHg}$ and evidence of LV systolic dysfunction was present in fourteen (29\%). The Wilkin's echo score for PTMC ranged between 7 and 11 with mean score of 8.6. Results of the PTMC using multi- track double balloon technique are shown in Table 1.

\section{Table 1}

PTMC Results

\begin{tabular}{lcccc}
\hline Parameter & $\begin{array}{c}\text { MVA } \\
\mathrm{cm} 2\end{array}$ & $\begin{array}{c}\text { LA pressure } \\
\mathrm{mmHg}\end{array}$ & $\begin{array}{c}\text { MR } \\
\text { grade }\end{array}$ & $\begin{array}{c}\text { NYHA } \\
\text { class }\end{array}$ \\
\hline Pre-PTMC & $\begin{array}{c}0.6 \pm 0.19 \\
(0.3-0.9)\end{array}$ & $\begin{array}{c}30.5 \pm 3.9 \\
(20-52)\end{array}$ & $1+$ & $3-4$ \\
& & & & \\
Post PTMC & $1.9 \pm 0.19$ & $11.5 \pm 3.8$ & & \\
& $(1.6-2.3)$ & $(4-9)$ & & $1-2$ \\
& $\mathrm{p}<0.001$ & $\mathrm{p}<0.001$ & $1+$ & $1-2$ \\
\hline
\end{tabular}

There were no significant intra-procedural complications in any of these patients and no mortality. One boy, however, had to be returned to the catheter laboratory for repeat ballooning due to technical difficulty in positioning balloons in an extremely small left ventricle and massive left atrium with greatly bulging atrium septum. One boy who had HIV/AIDS syndrome died later in hospital due to opportunistic infections. 


\section{DISCUSSION}

Over the last decade, PTMC has become the treatment of choice for symptomatic isolated mitral stenosis. The immediate results of PTMC are similar to those of closed and open surgical mitral commissurotomy $(10,11)$. The mean valve area usually doubles (from 1.0 $\mathrm{cm}^{2}$ - to $2.0 \mathrm{~cm}^{2}$ ), with a $50 \%$ to $60 \%$ reduction in transmitral gradient. Overall, $80 \%$ to $95 \%$ of the patients may have a successful procedure, which is defined as mitral valve are a $>1.5 \mathrm{~cm}^{2}$ and a decrease in left atrial pressure to $\leq 18 \mathrm{mmHg}$ in the absence of complications. Most of these results have been achieved with relatively older and bigger (mean weight) patients than our series. They also used different catheter systems (Inoue and traditional double balloon technique), which we prefered not to use due to unavailability of small enough sizes to suit the majority of our juvenile mitral stenosis patients. Nonetheless, our immediate results achieved $100 \%$ success with no mortality or significant complications from the procedure. Some of the patients were so young or so small that no other catheter system other than the multi-track system (which has balloon sizes down to $15 \mathrm{~mm}$ diameter and 5F access) would have managed. The clinical response to PTMC in this age group was dramatic with some patients unable to lie flat on the cathetarisation table at the beginning of the procedure and completely comfortable lying flat at the end of the procedure.

Data on long-term results of PTMC in juvenile mitral stenosis are scanty. Some randomised trials involving young patients have compared PTMC with both closed and open surgical commissurotomy(10-13). These trials consisted of patients aged 10 - 30 years with pliable mitral leaflets. There was no significant difference in acute haemodynamic results or complications rate between PTMC and surgery and early follow up data indicated no difference in haemodynamics, clinic improvement or exercise time. However, long-term follow up studies at three to seven years indicate more favourable haemodynamics and symptomatology with PTMC than with closed surgical commissurotomy $(11,13)$. Long-term PTMC results were equivalent to those of open surgical commissurotomy $(12,14)$. Some personal communications from "The Mitral Summit in Brasil" indicated 75\% event free survival at five years and $60-70 \%$ at 10 years. These results are somewhat inferior to those seen in the general population of mitral stenosis patients post PTMC. However, compared to the same age group of patients who underwent mitral valve replacement instead of PTMC almost 70\% had complications or needed reoperation at 10 years. Follow up in Kenya is a particular problem needing comprehensive solutions.

There have been concerns about possible rheumatic fever recurrences and occurrence of infective endocarditis post PTMC and surgical commissurotomy which would tend to limit the durations of benefits of intervention.
This calls for aggressive prophylaxis post intervention as a secondary prevention point of entry in the campaign against rheumatic fever in general. In conclusion, PTMC is safe and effective amongst our patients with juvenile mitral stenosis yielding satisfactory immediate results. Efforts should be made in identifying patients with the possibility of this diagnosis and referral for early intervention and subsequently effective follow up, post intervention.

\section{ACKNOWLEDGEMENTS}

To the cardiac catheterisation laboratory staff, medical colleagues who referred their patients to us, World Laboratory ICSC project MCD-4 for support and NuMed Inc. USA for donation of balloon catheters to needy patients.

\section{REFERENCES}

1. Aggarwal, B.L. Rheumatic heart disease unabated in developing countries. Lancet. 1981; 2:910-911.

2. Elsenberg, M.J. Rheumatic heart disease in developing countries:prevalance, prevention and control. Eur. Heart J. 1993; 14:122-128

3. Wood, P. An Appreciation of mitral stenosis part 1. Brit. Med. J. 1954; 1:1051-1063.

4. Rowe, J.C. Bland, E.F. and Sprague, H.B. The course mitral stenosis without surgery, ten and twenty year perspectives. Ann. Int. Med. 1960; 52:741-749.

5. Selzer, A. and Cohn, K.E. Natural history of mitral stenosis a review. Circulation. 1972; 45:878-890.

6. Yonga, G., Bonhoeffer, P. and Jowi, C. Percutaneous Balloon Mitral Valvotomy: Initial experience in Nairobi. East Afri. Med. J. 1999; 76:71-74.

7. Wilkins, G.T., Weyman, A.E., Abscal, V.M. and Block, P.C; Pallacios IF Percutaneous Mitral Balloon Dilatation:An analysis of echocardiographic variables related to outcome and the mechanism of dilatation. Brit. Heart J. 1988; 60:299-308.

8. Bonhoeffer, P., Piechaud, J.F., Sidi, D., Yonga, G.O.,Jowi C. et al. Mitral dilatation with the Multi-track system a new alternative approach. Cathet. Cardiovas. Diagn. 1995; 36:189-193.

9. Bonhoeeffer, P., Patel, T., Yonga, G., Jowi, C., Aggoun, Y. et al. Mitral Dilatation using Multi-track technique: international experience. J. Am. Coll. Cardiol. 1998; 31(5):255c.

10. Patel, J.J., Shama, D., Mitha, A.S, et al Balloon Valvuloplasty versus closed Commissurotomy for pliable mitral stenosis: a prospective haemodynamic study J. Am. Coll. Cardiol. 1991; 18:1318-1322

11. Arora, R., Nair, M., Kalra, G.S., Nigam, M. and Khaillulah $\mathrm{M}$. Immediate and long-term results of balloon and surgical closed mitral valvotomy: a randomized comparative study. Am Heart J. 1993, 125:1091-1094

12. Reyes, V.P., Raju, B.S., Wyne, J., et al. Percutaneous Balloon valvuloplasty compared with open surgical commissurotomy for mitral stenosis. N. Engl. J. Med. 1994; 331:961-967.

13. Ben Farhat, M., Ayari, M. and Maatouk. F, et al Percutaneous Balloon versus surgical closed and open mitral commissurotomy: seven year follow-up results of a randomized trial. Circulation. 1998; 97:245-250 